\title{
Effects of ezetimibe add-on therapy for high-risk patients with dyslipidemia
}

\author{
Minako Yamaoka-Tojo*1, Taiki Tojo², Rie Kosugi², Yuko Hatakeyama², \\ Yuki Yoshida ${ }^{2}$, Yoji Machida ${ }^{2}$, Naoyoshi Aoyama $^{2}$, Takashi Masuda ${ }^{1}$ and \\ Tohru Izumi ${ }^{2}$
}

\begin{abstract}
Address: ${ }^{1}$ Department of Rehabilitation, Kitasato University School of Allied Health Sciences, 1-15-1 Kitasato, Sagamihara, Kanagawa 228-8555, Japan and 2Department of Cardioangiology, Kitasato University School of Medicine, 1-15-1 Kitasato, Sagamihara, Kanagawa 228-8555, Japan

Email: Minako Yamaoka-Tojo* - myamaoka@med.kitasato-u.ac.jp; Taiki Tojo - ttojo@med.kitasato-u.ac.jp; Rie Kosugi - rie-k@zk9.so-net.ne.jp; Yuko Hatakeyama - yuko72@air.ocn.ne.jp; Yuki Yoshida - ANB41776@nifty.com; Yoji Machida - ymachida@med.kitasato-u.ac.jp; Naoyoshi Aoyama - aoyama@med.kitasato-u.ac.jp; Takashi Masuda - tak9999@med.kitasato-u.ac.jp;Tohru Izumi - izumi@med.kitasato-u.ac.jp * Corresponding author
\end{abstract}

Published: 12 October 2009

Lipids in Health and Disease 2009, 8:4I doi:I0.1186/I476-5IIX-8-4I

This article is available from: http://www.lipidworld.com/content/8/I/4I

(c) 2009 Yamaoka-Tojo et al; licensee BioMed Central Ltd.

This is an Open Access article distributed under the terms of the Creative Commons Attribution License (http://creativecommons.org/licenses/by/2.0), which permits unrestricted use, distribution, and reproduction in any medium, provided the original work is properly cited.
Received: 2 September 2009

Accepted: 12 October 2009

\begin{abstract}
Background: Ezetimibe (Zetia $\left.{ }^{\circledR}\right)$ is a potent inhibitor of cholesterol absorption that has been approved for the treatment of hypercholesterolemia. Statin, an inhibitor of cholesterol synthesis, is the first-choice drug to reduce low-density lipoprotein-cholesterol (LDL-C) for patients with hypercholesterolemia, due to its strong effect to lower the circulating LDL-C levels. Because a high dose of statins cause concern about rhabdomyolysis, it is sometimes difficult to achieve the guideline-recommended levels of LDL-C in high-risk patients with hypercholesterolemia treated with statin monotherapy. Ezetimibe has been reported to reduce LDL-C safely with both monotherapy and combination therapy with statins.

Results: To investigate the effect of ezetimibe as "add-on" therapy to statin on hypercholesterolemia, we examined biomarkers and vascular endothelial function in 14 patients with hypercholesterolemia before and after the 22-week ezetimibe add-on therapy. Ezetimibe addon therapy reduced LDL-C by $24 \%$ compared with baseline $(p<0.005)$, with 13 patients $(93 \%)$ reaching their LDL cholesterol goals. Of the Ezetimibe add-on therapy significantly improved not only LDL-C, high-density lipoprotein-cholesterol (HDL-C), and apolipoprotein (apo)B levels, but also reduced levels of triglyceride (TG), the ratio of LDL/HDL-C, the ratio of apoB/apoA-I, and a biomarker for oxidative stress (d-ROMs). Furthermore, ezetimibe add-on therapy improved vascular endothelial function in high-risk patients with hypercholesterolemia.
\end{abstract}

Conclusion: In conclusion, ezetimibe as add-on therapy to statin might be a therapeutic good option for high-risk patients with atherosclerosis.

\section{Background}

Atherosclerosis is the most common pathological process that leads to cardiovascular diseases, a disease of large- and medium-sized arteries that is characterized by formation of atherosclerotic plaques consisting of necrotic cores, calcified regions, accumulated modified lipids, 
inflamed endothelial cells, smooth muscle cells, leukocytes, and foam cells [1]. Although low-density lipoprotein (LDL) remains the most important and powerful risk factor for atherosclerosis, vascular inflammation- and oxidative stress-induced mechanisms of atherosclerosis have gained tremendous interest in the past 20 years [1-4]. LDL are susceptible to structural modifications by oxidation, particularly the small dense LDL particles. Under proatherogenic conditions, nitric oxide production from endothelial cells is reduced and the burden of reactive oxygen species (ROS) is increased $[5,6]$.

Ezetimibe (Zetia ${ }^{\circledast}$ ) is an epoch-making cholesterol transporter inhibitor in the small intestine to treat dyslipidemia patients with high levels of LDL-C [7]. The mechanism is absorption of both food-derived cholesterol $(\sim 25 \%)$ and bile acid-derived reabsorbed cholesterol ( $75 \%$ ). Generally, it is difficult to achieve the target LDL$\mathrm{C}$ levels by dietary therapy alone in patients with high LDL-C. HMG-CoA (or 3-hydroxy-3-methyl-glutaryl coenzyme A) reductase inhibitor, statin, is the first choice drug to reduce LDL-C for patients with high LDL-C, in that its strong effect to be lowered the circulating LDL-C levels. Because a high dose of statins cause concern about rhabdomyolysis, it is sometimes difficult to achieve the guideline-recommended levels of LDL-C in patients with high LDL-C treated with statin monotherapy. Ezetimibe has been reported to reduce LDL-C safely with both monotherapy and combination therapy with statins [8-10]. Ezetimibe is especially expected to be effective in statinintolerant patients with high LDL-C [11]. However, it is still unclear whether or not the LDL-C-lowering by ezetimibe is effective to suppress cardiovascular events or death [12].

In the present prospective study, we investigated the contribution of ezetimibe add-on therapy to the control of hypercholesterolemia in high-risk patients on statin mon- otherapy, especially focused on lipid profiles and endothelial function.

\section{Results}

To investigate the effect of ezetimibe as "add-on" therapy to statin on hypercholesterolemia, we examined biomarkers and vascular endothelial function in 14 high-risk patients for cardiovascular disease with hypercholesterolemia (Table 1). The add-on therapy of ezetimibe to statin monotherapy was safe and effective for the management of dyslipidemia in high-risk patients. After 22 weeks, ezetimibe add-on therapy reduced LDL-C by $24 \%$ compared with baseline $(\mathrm{p}<0.005)$, with 13 patients $(93 \%)$ reaching their LDL cholesterol goals. Of the Ezetimibe add-on therapy significantly improved not only LDL-C, high-density lipoprotein-cholesterol (HDL-C), and apolipoprotein (apo)B levels, but also reduced levels of triglyceride (TG) and d-ROMs (Table 2).

\section{Effects of ezetimibe on the ratio of LDL/HDL cholesterol in patients with hypercholesterolemia}

To determine atheroprotective effects of ezetimibe, we evaluated ratios of proatherogemic to antiatherogenic lipoprotein measurements, LDL-C to HDL-C ratio (LDL/ HDL-C) and apoB to apoA-I ratio (apoB/A-I). As shown in Figures 1 and 2, ezetimibe improved the ratio of LDL/ HDL-C and apoB/A-I. The most impressive data is that ezetimibe improved the ratio of LDL/HDL-C (by 28\%; from 2.6 to $1.9 ; \mathrm{p}=0.0037$ ) as shown in Figure 1. Furthermore, ezetimibe add-on therapy significantly reduced the ratio of apoB/A-I in high-risk patients with hypercholesterolemia (by $22 \%$; from 0.8 to $0.6 ; \mathrm{p}=0.0052$ ) as shown in Figure 2,.

\section{Effects of ezetimibe on a biomarker for oxidative stress in patients with hypercholesterolemia}

A large numbers of literature has linked oxidative stress with hypertension and atherosclerosis [13]. To examine

Table I: Baseline characteristics of the patients included the study

\begin{tabular}{|c|c|c|}
\hline Characteristic & & Value \\
\hline Age (year) & & $62 \pm 10$ \\
\hline Sex & Female & $5(36 \%)$ \\
\hline \multirow[t]{5}{*}{ Levels of vascular risk } & Coronary artery disease & II (79\%) \\
\hline & Diabetes mellitus & $6(43 \%)$ \\
\hline & Peripheral artery disease & I (7\%) \\
\hline & Stroke & $3(21 \%)$ \\
\hline & Hypertension & $10(71 \%)$ \\
\hline Statins & Strong statin & $9(64 \%)$ \\
\hline \multirow[t]{4}{*}{ Co-medication } & Renin-angiotensin system inhibitors & $14(100 \%)$ \\
\hline & $\beta$-blockers & II (79\%) \\
\hline & Aspirin & $10(7 \mid \%)$ \\
\hline & Antidiabetic agents & $4(3 \mid \%)$ \\
\hline
\end{tabular}

Data were shown as mean \pm SD or as percentages of the total number of patients. 
Table 2: Lipid and other biomarkers at baseline and after the ezetimibe add-on therapy

\begin{tabular}{llll}
\hline Biomarkers & Baseline & At 22 weeks of Ezetimibe add-on therapy & p-value \\
\hline Triglyceride $(\mathrm{mg} / \mathrm{dL})$ & $187 \pm 109$ & $134 \pm 66(-28 \%)$ & 0.010 \\
LDL-cholesterol $(\mathrm{mg} / \mathrm{dL})$ & $134 \pm 20$ & $102 \pm 13(-24 \%)$ & 0.020 \\
HDL-cholesterol (mg/dL) & $52 \pm 11$ & $56 \pm 10$ & 0.612 \\
Free fatty acid $(\mu \mathrm{Eq} / \mathrm{L})$ & $377 \pm 232$ & $379 \pm 204$ & 0.726 \\
RLP-cholesterol $(\mathrm{mg} / \mathrm{dL})$ & $9.9 \pm 7.0$ & $8.8 \pm 5.3$ & 0.188 \\
Apolipoprotein B (mg/dL) & $107 \pm 17$ & $87 \pm 12(-18 \%)$ & 0.004 \\
Apolipoprotein A-I (mg/dL) & $134 \pm 22$ & $141 \pm 23$ & 0.121 \\
MDA-LDL (mg/dL) & $113 \pm 28$ & $100 \pm 28(-12 \%)$ & 0.039 \\
Glucose (mg/dL) & $118 \pm 24$ & $110 \pm 16$ & 0.152 \\
HbAlc $(\%)$ & $5.9 \pm 0.7$ & $6.0 \pm 0.8$ & 0.531 \\
hs-CRP (mg/dL) & $0.11 \pm 0.09$ & $0.13 \pm 0.18$ & 0.872 \\
dROMs (U Carr) & $368 \pm 47$ & $329 \pm 45(-11 \%)$ & 0.014 \\
\end{tabular}

Data are expressed as mean \pm SD or as number (\%). The Student's paired $t$-test was used for pairwise comparisons between values before and after administration of ezetimibe for 22 weeks $(n=14)$. RLP, remnant lipoprotein; MDA, malondialdehyde-modified; hs-CRP, high-sensitivity C reactive protein; dROMs, derivatives of the reactive oxidative metabolites.

whether ezetimibe improves oxidative stress or not, we measured the derivatives of reactive oxidative metabolites (d-ROMs) test as an oxidative biomarker in patients with hypercholesterolemia before and after the ezetimibe addon therapy with a statin (Table 2). As shown in Figure 3, the ezetimibe add-on therapy remarkably reduced $\mathrm{d}$ ROMs levels in high-risk patients with hypercholesterolemia $(11 \%$ reduction, $\mathrm{p}=0.014)$.

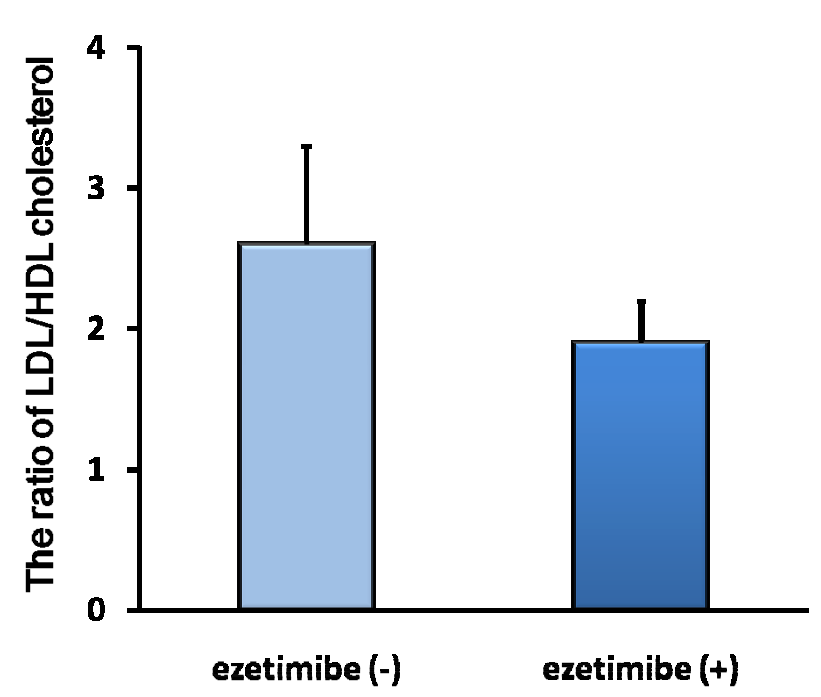

Figure I

Ezetimibe improved LDL/HDL-cholesterol ratio in patients with hypercholesterolemia. Ezetimibe improved LDL/HDL-cholesterol ratio in patients with hypercholesterolemia. LDL- and HDL-cholesterol were measured before and after 22-week ezetimibe administration in patients with atherosclerosis-prone hypercholesterolemia ( $\mathrm{n}$ $=14$ ). Bars represent the mean value of the ratio \pm SD.

\section{Effects of ezetimibe on vascular endothelial function in patients with hypercholesterolemia}

Vascular endothelial dysfunction has been considered as the first step of atherosclerosis, we examined endothelial function using a fingertip peripheral arterial tonometry device system, EndoPAT ${ }^{\mathrm{Tm}}$ (Itamar Medical Ltd., Caesarea, Israel), as a surrogate marker for cardiovascular events. After 22 weeks of ezetimibe add-on combination therapy

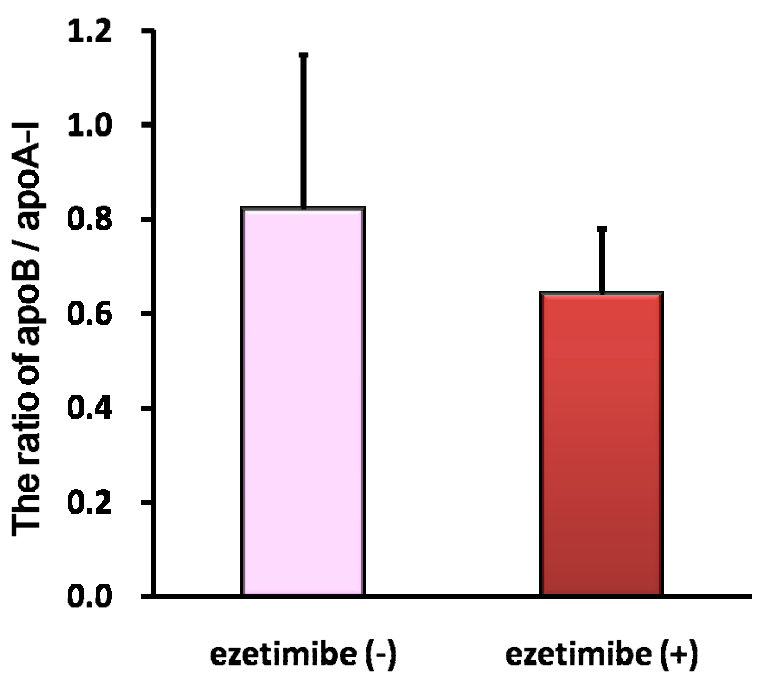

Figure 2

Ezetimibe improved apolipoprotein B (apoB) to apolipoprotein A-I (apoA-I) ratio in patients with hypercholesterolemia. Ezetimibe improved apoB to apoA-I ratio in patients with hypercholesterolemia. apoB and apoA were measured before and after 22-week ezetimibe administration in patients with atherosclerosis-prone hypercholesterolemia $(n=14)$. Bars represent the mean value of the ratio \pm SD. 


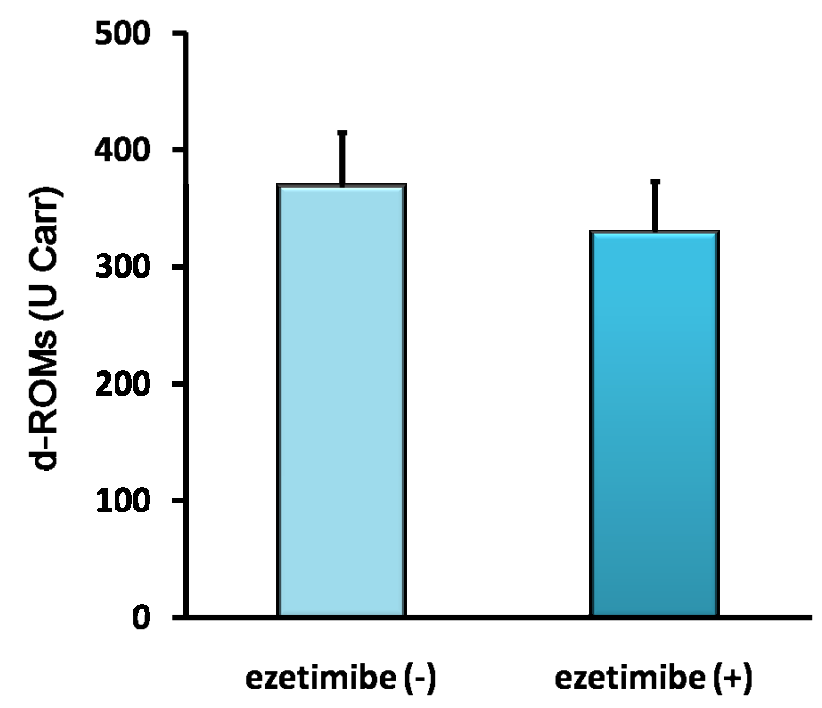

Figure 3

Ezetimibe reduced a circulating oxidative marker, derivatives of reactive oxidative metabolites (dROMs), in patients with atherosclerosis-prone with hypercholesterolemia. Measurements of $d-R O M s$ were assessed before and after 22-week ezetimibe administration in patients with atherosclerosis-prone hypercholesterolemia $(n=14)$. Bars represent the mean value of the ratio \pm SD.

with a statin, reactive hyperemia index (RHI) measured by the EndoPAT ${ }^{\mathrm{TM}}$ was improved in high-risk patients with hypercholesterolemia (Figure 4). Overall, there was a 14\% increase in RHI at the 22nd week (from 1.31 to 1.53 ; $\mathrm{p}=$ $0.020)$. According to a literature [14], an RHI $<1.35$ was found to have a sensitivity of $80 \%$ and a specificity of $85 \%$ to identify patients with coronary endothelial dysfunction.

\section{Discussion}

Our results suggest that the add-on therapy of ezetimibe to statin monotherapy is safe and effective for the management of dyslipidemia in high-risk patients. In the present study, we clearly showed that ezetimibe add-on therapy reduced levels of LDL-C and apoB as well as TG and dROMs.

Ezetimibe, a novel lipid-lowering agent, selectively inhibits intestinal cholesterol absorption, reducing total cholesterol and TG levels and also reducing the development of atherosclerosis in apoE knockout mice $[15,16]$. A sterol transporter, Niemann-Pick C1-Like 1 (NPC1L1) is involved in subcellular cholesterol trafficking and plays a critical role in the absorption of intestinal cholesterol $[17,18]$. NPC1L1-deficient mice exhibit a substantial reduction in absorbed cholesterol, on which ezetimibe

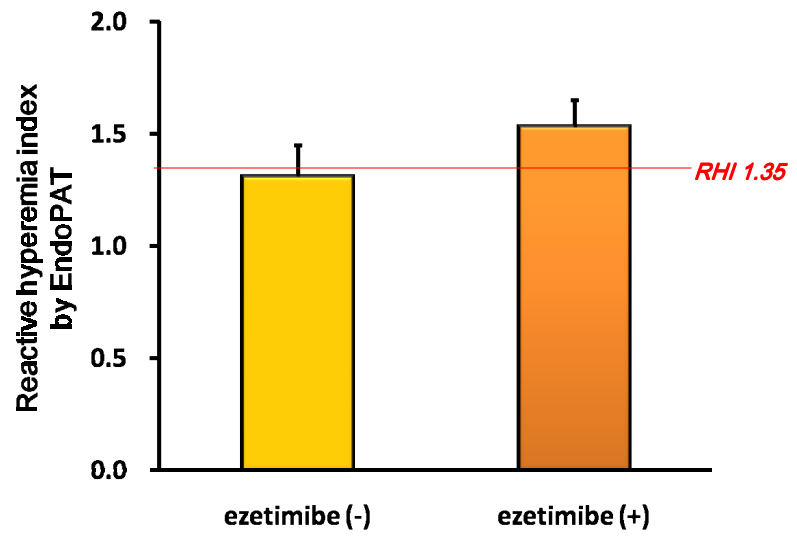

Figure 4

Ezetimibe improved reactive hyperemia index $(\mathrm{RHI})$ by EndoPAT ${ }^{\mathrm{TM}}$ in patients with hypercholesterolemia. RHI were measured before and after 22-week ezetimibe administration in patients with hypercholesterolemia $(n=14)$. According to Bonetti P.O., et al, [14], an RHI $<\mathrm{I} .35$ was found to have a sensitivity of $80 \%$ and a specificity of $85 \%$ to identify patients with coronary endothelial dysfunction. Bars represent the mean value of the ratio $\pm S D$.

had no effect [18]. Thereafter, the molecular target of ezetimibe was revealed to be NPC1L1, which is a critical mediator of cholesterol absorption and an essential component of ezetimibe-sensitive pathway [16].

The most impressive data is that ezetimibe improved the ratio of LDL/HDL-C $(\mathrm{p}<0.005)$ as shown in Figure 1. According to a recent literature, the lipid ratio of LDL/ HDL-C is better monitoring predictors than single standard lipids including total cholesterol, LDL-C, and HDL-C [19]. As for initial risk measurements, several previous cohort studies and a meta-analysis study suggest that the ratio of LDL/HDL-C also have greater independent predictive values for coronary heart disease than individual serum total cholesterol or LDL-cholesterol levels [20-24]. In the current therapy for hypercholesterolemia, ezetimibe may be the most powerful agent to improve the LDL/HDL ratio compared to any statin monotherapy. Furthermore, ezetimibe add-on therapy significantly reduced the ratio of apoB to apoA-I in high-risk patients with hypercholesterolemia ( $\mathrm{p}<0.01$, Figure 2$)$. Patients who were treated adequately according to current guidelines (i.e., LDL cholesterol $\leq 100 \mathrm{mg} / \mathrm{dL}$ ) still had residual major cardiovascular event risks that could be recognized by the evaluation of levels of non-HDL cholesterol or apoB [22]. On-treatment levels of non-HDL cholesterol and $\mathrm{apoB}$ are considered to be more closely associated with cardiovascular outcome than levels of LDL cholesterol [25]. These data suggest that ezetimibe not only 
reduced serum levels of LDL cholesterol but also improve total lipid profiles.

A large number of reports in the literature has linked oxidative stress with hypertension and atherosclerosis [13]. The ezetimibe add-on therapy remarkably reduced an oxidative stress marker in high-risk patients with hypercholesterolemia (Figure 3). Considering that ezetimibe monotherapy or a combination therapy with simvastatin decreased LDL tendency to peroxidation, ezetimibe may have favorable pleiotropic effects beyond the LDL-cholesterol lowering $[26,27]$. These data suggest that ezetimibe could contribute to atheroprotective properties through effective antioxidant actions. Since oxidized LDL induces expression of a nicotinamide adenine dinucleotide phosphate (NADPH) oxidase, gp91phox, and ROS generation in vascular endothelial cells [28], ezetimibe may attenuate ROS production through reduction of circulating ox-LDL in patients with hypercholesterolemia.

Endothelial dysfunction is the initial step of atherosclerosis. A recent report demonstrated that ezetimibe treatment attenuated vascular functions, such as endothelial dysfunction, oxidative stress, and inflammation in high-fat fed apoE-deficient mice [29]. Ezetimibe treatment markedly inhibited the development of lipid-rich plaque and also significantly improved endothelial dysfunction assessed by the vasodilator response to acetylcholine [30], accompanied by inhibition of interleukin- 6 mRNA and an increase in endothelial nitric oxide synthase mRNA in the aorta. Furthermore, ezetimibe suppressed ROS generation and the ubiquitination-proteasome system in the aorta. In the present study, ezetimibe add-on therapy achieved effective RHI-improvement in high-risk patients with hypercholesterolemia $(\mathrm{p}<0.05$, Figure 4$)$. To our knowledge, this is the first clinical data about ezetimibeimproving vascular endothelial function detected by EndoPAT.

NPC1L1 is widely expressed in many human tissues, with the highest expression in the small intestine as well as in the liver [31,32]. Therefore, ezetimibe inhibits cholesterol absorption in the small intestine, reduces enterohepatic circulation of cholesterol, reduces uptake of free cholesterol in hepatocytes, and should affect metabolic pathways in the liver [33]. Ezetimibe improved hepatic insulin signaling as well as hepatic steatosis in Zucker Obese fatty (ZOF) rats. Ezetimibe also restored insulin sensitivity in steatotic hepatocytes in vitro by a reduction in hepatic ROS generation, Janus-family tyrosine kinase (JNK) activation, and endoplasmic reticulum stress. In addition, ezetimibe recovered insulin-induced Akt activation, and reduced gluconeogenic genesin the liver of ZOF rats and cultured steatotic hepatocytes [33]. Other studies have shown that ROS-dependent activation of JNK plays a role in the devel- oping insulin resistance [34-36]. In recent clinical studies, ezetimibe treatment has been considered as an effective therapeutic option for non-alcoholic fatty liver disease (NAFLD) $[31,37,38]$. Several reports have concluded that ezetimibe monotherapy not only protects against high fat diet-induced dyslipidemia but also attenuates liver steatosis in an experimental NAFLD model $[39,40]$. In apoE knockout mice, liver weight was significantly decreased and lipid accumulation in the liver was also dramatically inhibited in the ezetimibe-treated group [29]. These accumulating data suggest that the inhibition of NPC1L1dependent cholesterol uptake by ezetimibe may be a suitable therapeutic target for treatment of not only hypercholesterolemia but also broader aspects of metabolic disorders in patients with type 2 diabetes and/or metabolic syndrome (Figure 5).

\section{Conclusion}

Our results suggest that ezetimibe improves lipid profiles, reduces oxidative stress, and improve endothelial function in high-risk patients with dyslipidemia, which may contribute to prevention atherosclerosis in vasculature. As an atheroprotective drug, ezetimibe may be a suitable therapeutic target for treatment of not only hypercholesterolemia but also broader aspects of metabolic disorders in patients with type 2 diabetes or metabolic syndrome or both.

\section{Methods \\ Subjects}

The study included 14 Japanese high-risk patients (36\% female) with coronary artery disease or equivalents treated with statin monotherapy in the Department of Cardioangiology, Kitasato University Hospital. No patients achieved the guideline-recommended levels of LDL-C $[41,42]$, concretely, LDL-C $<100 \mathrm{mg} / \mathrm{dL}$ for coronary artery disease patients and $<120 \mathrm{mg} / \mathrm{dL}$ for high-risk patients with diabetes, cerebrovascular disease, and/or peripheral arterial occlusive disease. Ezetimibe from Bayer Co., Ltd. (Osaka, Japan) and Schering-Plough K.K. (Tokyo, Japan) was administered once a day $(10 \mathrm{mg} / \mathrm{day})$ to all patients for 22 weeks. Lipid profiles, biochemical parameters, and adverse effects were monitored every 4-8 week through the study. None of the patients took any other drugs and/or any advice for diet and lifestyle modification that affect lipid profile or lipid metabolism. Except the ezetimibe add-on therapy, every medication was continued without any dose changes during the study period. Total calorie intake and composition of the diet were kept constant for each patient.

All subjects gave written informed consent before participating in this study, and the ethics committee of the Kitasato University Hospital approved the study design. 


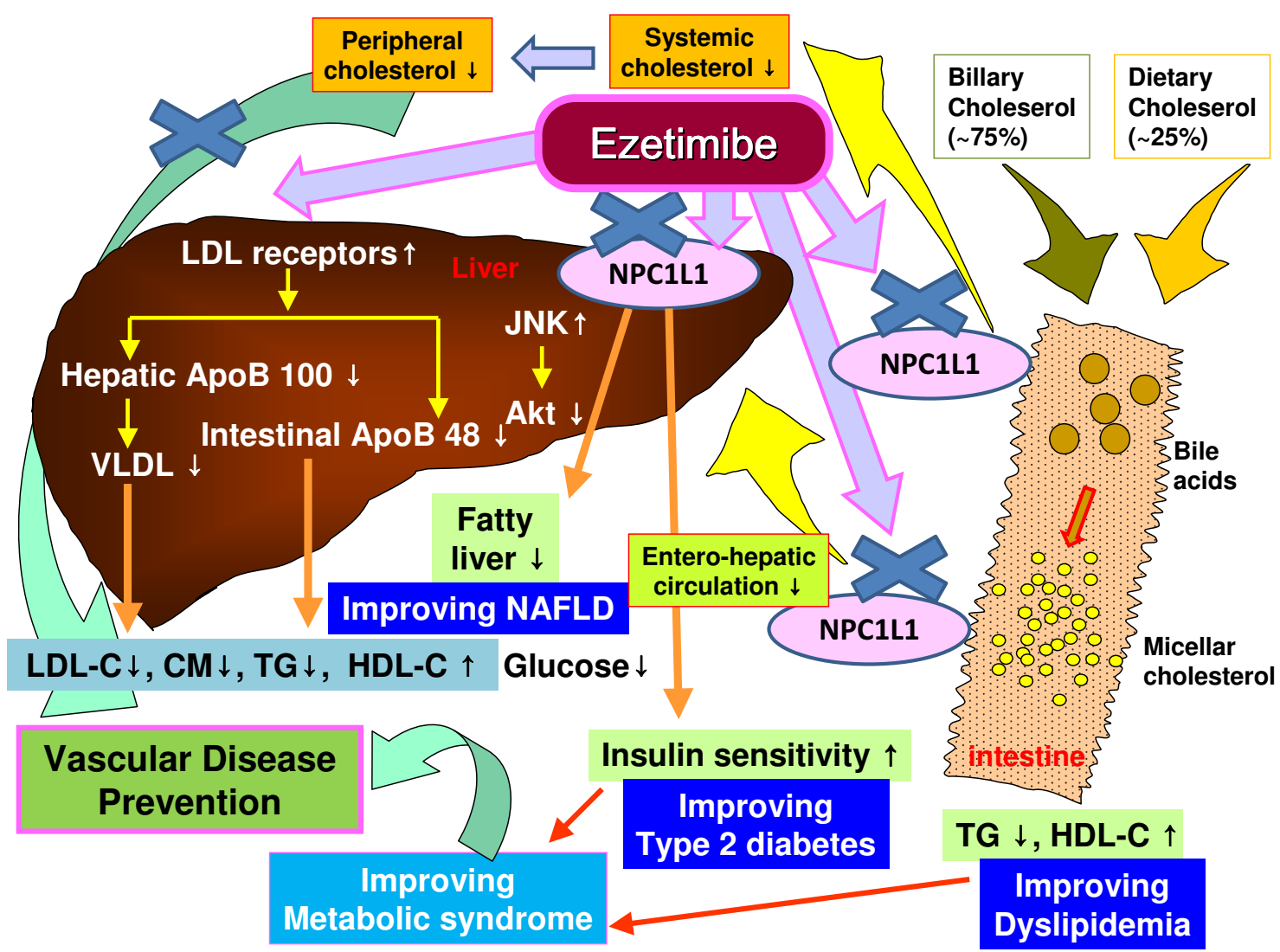

Figure 5

Schematic diagram of the proposed mechanisms of ezetimibe-induced atheroprotective effects. LDL-C, lowdensity lipoprotein-cholesterol; ox-LDL, oxidized LDL; VEGF, vascular endothelial growth factor; LPS, lipopolysaccharide; MCP-I, monocyte chemotactic protein-I; CM, chylomicrons; TG, triglyceride; HDL-C, high-density lipoprotein-cholesterol; NAFLD, non-alcoholic fatty liver disease; NPCILI, Nieman-Pick CI-like I; apoB, apolipoprotein B; VLDL, very-low density lipoprotein; JNK, Janus-family tyrosine kinase.

\section{Measurement of serum sample}

Fasting blood samples were taken from each of the 14 enrolled patients before and after the ezetimibe add-on study. Serum was centrifuged ( $1500 \mathrm{~g}$ for $15 \mathrm{~min}$ at $4^{\circ} \mathrm{C}$ ) and stored at $4^{\circ} \mathrm{C}$ until measurement within couple days for biochemical markers, such as TG, LDL-C, HDL-C, alanine aminotransferase, aspartate aminotransferase, serum creatinine, creatine kinase, free fatty acid, remnant lipoprotein-cholesterol, apoB, apoA-I, malondialdehydemodified-LDL, glucose, HbA1c, and high-sensitivity C reactive protein.

\section{Measurement of $\mathrm{d}-\mathrm{ROMs}$}

Serum was centrifuged (1500 $\mathrm{g}$ for $15 \mathrm{~min}$ at $4^{\circ} \mathrm{C}$ ) and stored at $-20^{\circ} \mathrm{C}$ until measurement within one week for free oxygen radical monitor, d-ROMs. The d-ROMs were evaluated spectrophotometrically by Free Radical Analyti- cal System (FRAS4 ${ }^{\circledR}$, Diacron International, Grosseto, Italy) $[43,44]$. The d-ROMs test is based on the ability of transition metals to catalyze, in the presence of peroxides, the formation of free radicals which are then trapped by an alchylamine. The alchylamine reacts forming a colored radical detectable at $505 \mathrm{~nm}$ through a kinetic reaction which is linear up to $500 \mathrm{U}$ Carr (Carratelli units). The determination of free radicals can be made with a normal spectrophotometer. The normal range has been determined as 250-300 U Carr [43].

\section{Measurement of vascular endothelial function by EndoPAT}

Vascular endothelial function was examined reactive hyperemia by EndoPAT ${ }^{\mathrm{TM}}$ [45] in patients with hypercholesterolemia. Using a fingertip peripheral arterial tonometry device, we measured digital pulse amplitude in 
patients with hypercholesterolemia for 5 minutes at baseline and after a reactive hyperemia induced by a 5-minute forearm cuff occlusion. RHI was measured before and after 22-week ezetimibe administration in patients with hypercholesterolemia.

\section{Statistical analysis}

The results were expressed as mean \pm SD. The Student's paired $t$-test was used for patients between values before and after ezetimibe administration. A value of $\mathrm{p}<0.05$ was considered to be statistically significant.

\section{Competing interests}

The authors declare that they have no competing interests.

\section{Authors' contributions}

MY-T participated in the design of the study and performed the statistical analysis. TT conceived of the study, and participated in its design and coordination and helped to draft the manuscript. Other authors participated in enrolling patients in the study. All authors read and approved the final manuscript.

\section{Acknowledgements}

This work was partly supposed by Grants 21790743 (M.Y.-T.) and 21790744 (to T.T.) from the Ministry of Education, Culture, Science and Technology of Japan.

\section{References}

I. Ross R: Atherosclerosis--an inflammatory disease. The New England journal of medicine 1999, 340(2): I I5- I 26.

2. Hansson GK, Libby P: The immune response in atherosclerosis: a double-edged sword. Nature reviews 2006, 6(7):508-519.

3. Weber C, Zernecke A, Libby P: The multifaceted contributions of leukocyte subsets to atherosclerosis: lessons from mouse models. Nature reviews 2008, 8(10):802-8I5.

4. Galkina E, Ley K: Immune and inflammatory mechanisms of atherosclerosis (*). Annual review of immunology 2009, 27: 165-197.

5. Andrews HE, Bruckdorfer KR, Dunn RC, Jacobs M: Low-density lipoproteins inhibit endothelium-dependent relaxation in rabbit aorta. Nature 1987, 327(6 I |9):237-239.

6. Cai H, Harrison DG: Endothelial dysfunction in cardiovascular diseases: the role of oxidant stress. Circulation research 2000, 87(10):840-844.

7. Bays HE, Moore PB, Drehobl MA, Rosenblatt S, Toth PD, Dujovne CA, Knopp RH, Lipka LJ, Lebeaut AP, Yang B, et al.: Effectiveness and tolerability of ezetimibe in patients with primary hypercholesterolemia: pooled analysis of two phase II studies. Clinical therapeutics 200I, 23(8): I209-1230.

8. Drazen JM, Jarcho JA, Morrissey S, Curfman GD: Cholesterol lowering and ezetimibe. The New England journal of medicine 2008, 358(I 4): I507-I508.

9. Jackevicius CA, Tu JV, Ross JS, Ko DT, Krumholz HM: Use of ezetimibe in the United States and Canada. The New England journal of medicine 2008, 358(17): $1819-1828$.

10. Kastelein JJ, Akdim F, Stroes ES, Zwinderman AH, Bots ML, Stalenhoef AF, Visseren FL, Sijbrands EJ, Trip MD, Stein EA, et al.: Simvastatin with or without ezetimibe in familial hypercholesterolemia. The New England journal of medicine 2008, 358(14): | $43|-| 443$.

II. Athyros VG, Tziomalos K, Kakafika Al, Koumaras H, Karagiannis A, Mikhailidis DP: Effectiveness of ezetimibe alone or in combination with twice a week Atorvastatin $(10 \mathrm{mg})$ for statin intolerant high-risk patients. The American journal of cardiology 2008, I 01 (4):483-485.
12. Brown BG, Taylor A): Does ENHANCE diminish confidence in lowering LDL or in ezetimibe? The New England journal of medicine 2008, 358( I 4): I 504-I 507.

13. Harrison D, Griendling KK, Landmesser U, Hornig B, Drexler H: Role of oxidative stress in atherosclerosis. The American journal of cardiology 2003, 9 I(3A):7A- I IA

14. Bonetti PO, Pumper GM, Higano ST, Holmes DR Jr, Kuvin JT, Lerman A: Noninvasive identification of patients with early coronary atherosclerosis by assessment of digital reactive hyperemia. Journal of the American College of Cardiology 2004, 44(I I):2 I37-2 I 4 I.

15. Davis HR Jr, Compton DS, Hoos L, Tetzloff G: Ezetimibe, a potent cholesterol absorption inhibitor, inhibits the development of atherosclerosis in ApoE knockout mice. Arteriosclerosis, thrombosis, and vascular biology 200 I, 2I(I 2):2032-2038.

16. Garcia-Calvo M, Lisnock J, Bull HG, Hawes BE, Burnett DA, Braun MP, Crona JH, Davis HR Jr, Dean DC, Detmers PA, et al.: The target of ezetimibe is Niemann-Pick CI-Like I (NPCILI). Proceedings of the National Academy of Sciences of the United States of America 2005, 102(23):8I32-8137.

17. Davies JP, Levy B, loannou YA: Evidence for a Niemann-pick $\mathbf{C}$ (NPC) gene family: identification and characterization of NPCILI. Genomics 2000, 65(2): I37-145.

18. Altmann SW, Davis HR Jr, Zhu LJ, Yao X, Hoos LM, Tetzloff G, lyer SP, Maguire M, Golovko A, Zeng M, et al.: Niemann-Pick CI Like I protein is critical for intestinal cholesterol absorption. Science (New York, NY) 2004, 303(566 I): I 20I-I 204

19. Takahashi O, Glasziou PP, Perera R, Shimbo T, Suwa J, Hiramatsu S, Fukui T: Lipid Re-screening: What Is the Best Measure and Interval? Heart 2009 in press.

20. Kinosian B, Glick H, Garland G: Cholesterol and coronary heart disease: predicting risks by levels and ratios. Annals of internal medicine 1994, I 2 I(9):64I-647.

21. Ridker PM, Rifai N, Cook NR, Bradwin G, Buring JE: Non-HDL cholesterol, apolipoproteins A-I and B I00, standard lipid measures, lipid ratios, and CRP as risk factors for cardiovascular disease in women. Jama 2005, 294(3):326-333.

22. Ingelsson E, Schaefer EJ, Contois JH, McNamara JR, Sullivan L, Keyes MJ, Pencina MJ, Schoonmaker C, Wilson PW, D'Agostino RB, et al:: Clinical utility of different lipid measures for prediction of coronary heart disease in men and women. Jama 2007, 298(7):776-785.

23. Lemieux I, Lamarche B, Couillard C, Pascot A, Cantin B, Bergeron I, Dagenais GR, Despres JP: Total cholesterol/HDL cholesterol ratio vs LDL cholesterol/HDL cholesterol ratio as indices of ischemic heart disease risk in men: the Quebec Cardiovascular Study. Archives of internal medicine 200 I, I6 I (22):2685-2692.

24. Goswami B, Rajappa M, Mallika V, Kumar S, Shukla DK: Apo-B/apoAl ratio: a better discriminator of coronary artery disease risk than other conventional lipid ratios in Indian patients with acute myocardial infarction. Acta cardiologica 2008, 63(6):749-755.

25. Kastelein JJ, Steeg WA van der, Holme I, Gaffney M, Cater NB, Barter P, Deedwania P, Olsson AG, Boekholdt SM, Demicco DA, et al.: Lipids, apolipoproteins, and their ratios in relation to cardiovascular events with statin treatment. Circulation 2008, I I 7(23):3002-3009.

26. Hussein O, Minasian L, Itzkovich Y, Shestatski K, Solomon L, Zidan J: Ezetimibe's effect on platelet aggregation and LDL tendency to peroxidation in hypercholesterolaemia as monotherapy or in addition to simvastatin. British journal of clinical pharmacology 2008, 65(5):637-645.

27. Nakamura T, Sato E, Fujiwara N, Kawagoe $Y$, Ueda $Y$, Suzuki T, Ueda S, Adachi H, Okuda S, Yamagishi SI: Ezetimibe decreases serum levels of asymmetric dimethylarginine (ADMA) and ameliorates renal injury in non-diabetic chronic kidney disease patients in a cholesterol-independent manner. Pharmacol Res 2009 in press.

28. Zhao R, Ma X, Xie X, Shen GX: Involvement of NADPH oxidase in oxidized LDL-induced upregulation of heat shock factor-I and plasminogen activator inhibitor- $I$ in vascular endothelial cells. American journal of physiology 2009, 297(I):EI04-III.

29. Nakagami H, Osako MK, Takami Y, Hanayama R, Koriyama H, Mori M, Hayashi H, Shimizu H, Morishita R: Vascular protective effects of ezetimibe in ApoE-deficient mice. Atherosclerosis 2009 , 203(I):5I-58. 
30. Hayashi K, Nakamura S, Morishita R, Moriguchi A, Aoki M, Matsumoto $K$, Nakamura T, Kaneda $Y$, Sakai N, Ogihara T: In vivo transfer of human hepatocyte growth factor gene accelerates re-endothelialization and inhibits neointimal formation after balloon injury in rat model. Gene therapy 2000, 7(19): |664-167|.

31. Davies JP, Scott C, Oishi K, Liapis A, loannou YA: Inactivation of NPCI L I causes multiple lipid transport defects and protects against diet-induced hypercholesterolemia. The Journal of biological chemistry 2005, 280(13): | 27| |0- I 2720.

32. Sane AT, Sinnett D, Delvin E, Bendayan M, Marcil V, Menard D, Beaulieu JF, Levy E: Localization and role of NPCILI in cholesterol absorption in human intestine. Journal of lipid research 2006, 47(10):2 $112-2120$.

33. Nomura M, Ishii H, Kawakami A, Yoshida M: Inhibition of Hepatic Neiman-Pick CI-Like I Improves Hepatic Insulin Resistance. American journal of physiology 2009 in press.

34. Hirosumi J, Tuncman G, Chang L, Gorgun CZ, Uysal KT, Maeda K, Karin M, Hotamisligil GS: A central role for JNK in obesity and insulin resistance. Nature 2002, 420(69 I3):333-336.

35. Conde de la Rosa L, Schoemaker MH, Vrenken TE, Buist-Homan M, Havinga R, Jansen PL, Moshage H: Superoxide anions and hydrogen peroxide induce hepatocyte death by different mechanisms: involvement of JNK and ERK MAP kinases. Journal of hepatology 2006, 44(5):918-929.

36. Schwabe RF, Brenner DA: Mechanisms of Liver Injury. I. TNF alpha-induced liver injury: role of IKK, JNK, and ROS pathways. Am J Physiol Gastrointest Liver Physiol 2006, 290(4):G583-589.

37. Yamagishi S, Nakamura K, Matsui T, Sato T, Takeuchi M: Inhibition of intestinal cholesterol absorption by ezetimibe is a novel therapeutic target for fatty liver. Medical hypotheses 2006, 66(4):844-846.

38. Hughes EA, Tracey I, Singhal S, Patel J: Unexpected beneficial effect in the use of ezetimibe in non-alcoholic fatty liver disease. Medical hypotheses 2006, 67(6): |463-|464.

39. Zheng S, Hoos L, Cook J, Tetzloff G, Davis H Jr, van Heek M, Hwa J]: Ezetimibe improves high fat and cholesterol diet-induced non-alcoholic fatty liver disease in mice. European journal of pharmacology 2008, 584(I): I I8-I 24.

40. Deushi M, Nomura M, Kawakami A, Haraguchi M, Ito M, Okazaki M, Ishii $H$, Yoshida M: Ezetimibe improves liver steatosis and insulin resistance in obese rat model of metabolic syndrome. FEBS letters 2007, 58I(29):5664-5670.

4I. Teramoto T, Sasaki J, Ueshima H, Egusa G, Kinoshita M, Shimamoto K, Daida H, Biro S, Hirobe K, Funahashi T, et al:: Diagnostic criteria for dyslipidemia. Executive summary of Japan Atherosclerosis Society (JAS) guideline for diagnosis and prevention of atherosclerotic cardiovascular diseases for Japanese. Journal of atherosclerosis and thrombosis 2007, I4(4): I55-I58.

42. Teramoto T, Sasaki J, Ueshima H, Egusa G, Kinoshita M, Shimamoto K, Daida H, Biro S, Hirobe K, Funahashi T, et al.: Executive summary of Japan Atherosclerosis Society (JAS) guideline for diagnosis and prevention of atherosclerotic cardiovascular diseases for Japanese. Journal of atherosclerosis and thrombosis 2007 , I 4(2):45-50.

43. Cesarone MR, Belcaro G, Carratelli M, Cornelli U, De Sanctis MT, Incandela L, Barsotti A, Terranova R, Nicolaides A: A simple test to monitor oxidative stress. Int Angiol 1999, I 8(2): I27-I30.

44. Parmigiani S, Gambini L, Massari A, Pezzani I, Payer C, Bevilacqua G: Evaluation of reactive oxygen metabolites with micromethod in neonates: determination of standards of normality in full-term babies. Acta Biomed Ateneo Parmense 1997, 68(Suppl I): 103-106.

45. Faizi AK, Kornmo DW, Agewall S: Evaluation of endothelial function using finger plethysmography. Clinical physiology and functional imaging 2009, 29(5):372-375.

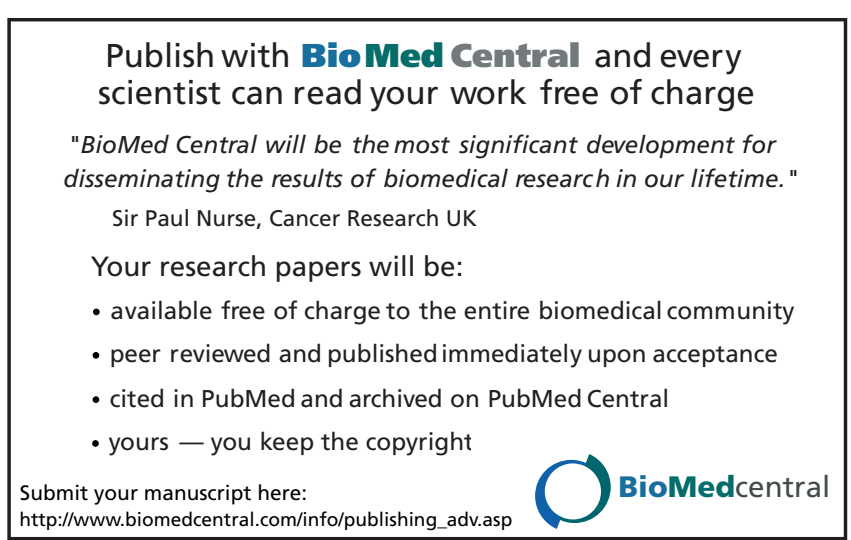

